\title{
BMR
}

\section{Changes in expression of specific miRNAs and their target genes in repair of exercise- induced muscle injury in rats}

\author{
W. Wu \\ School of Physical and Health Education, Mianyang Normal University, \\ Mianyang, Sichuan, China \\ Corresponding author: W. Wu \\ E-mail: skfj4215@163.com
}

Genet. Mol. Res. 15 (3): gmr.15038698

Received April 6, 2016

Accepted July 25, 2016

Published September 16, 2016

DOI http://dx.doi.org/10.4238/gmr.15038698

Copyright (C) 2016 The Authors. This is an open-access article distributed under the terms of the Creative Commons Attribution ShareAlike (CC BY-SA) 4.0 License.

\begin{abstract}
The effects of muscle-specific miRNAs in the repair of exercise-induced muscle injury were investigated by examining the changes in their expression and that of the target genes in rat skeletal muscle. Two-month-old agile male rats were randomly divided into exercise and static control groups, the former subdivided into $0-\mathrm{h}, 6-\mathrm{h}$, 12-h, 1-day, 2-day, 3-day, 1-week, and 2-week groups based on time after exercise. Left gastrocnemii of rats were hematoxylin-eosin stained whereas the right gastrocnemii were used for expression analysis of muscle-specific miRNAs (miR-1 and miR-206) and their target genes, Cx43 and HDAC. Cellular swelling and increased cell volume and intercellular spaces were observed histologically in the 0-h group. Unlike the control group, cells continued to swell whereas intercellular spaces decreased slightly, in the 6-h, 12-h, 1-day, and 2-day groups. Cell swelling was most serious in the 3-day group. In the 1-week group, inflammatory cell infiltration decreased and in the 2-week group, repair
\end{abstract}


was almost complete. The differences in miR-1 expression between the groups were neither obvious nor significant. miR-206 expression increased; however, it differed significantly from that in group $\mathrm{C}$ only in the 1-week group. Cx43 and HDAC4 mRNA expression first decreased and then increased compared to that in the control group; differences in HDAC4 mRNA expression were significant in the 1-week group. Compared to the control group, the differences in $\mathrm{Cx} 43$ protein levels were significant in the 0 -h and 3-day groups. Thus, miR-206 and $\mathrm{Cx} 43$ are involved in the repair of exercise-induced muscle injury.

Key words: Downstream target genes; Injury repair; miR-1; miR-206; miRNAs; Rats

\section{INTRODUCTION}

Skeletal muscle, which responds to the stimulation of external factors and intracorporal physiological environment, plays an important role in sport and energy metabolism (Davis and Fiorotto, 2009). Some myogenic transcription factors regulate the mechanisms for development of vertebrate muscle at genetic level. By regulating myoblast proliferation, migration, and conversion of muscle fiber type, these mechanisms also affect muscle hypertrophy and functional differentiation (Braun and Gautel, 2011). Skeletal muscle regeneration includes the injury, repair, and reconstruction phases (Hara et al., 2011; Dey et al., 2014). In the injury phase, cells show necrosis, along with vascular rupture, blood clotting, and a production of a large number of inflammatory cells. In the repair phase, cellular debris is removed by the immune system and new muscle fibers are formed through the activation of satellite cells (Maltzahn et al., 2014). In the reconstruction stage, the newly formed muscle fibers mature and can be assembled as skeletal muscle (Dixon, 2009). Both the development and regeneration process involve the activation of satellite cells as well as the control of proliferation, cycle and differentiation of muscle cells. Therefore, for muscle development and regeneration, it is vital to study the regulation of cell proliferation and differentiation.

MicroRNA (miRNA) is a kind of endogenous RNA molecule, 20-24 nt in length, which is widely expressed in various tissues and has evolutionarily conserved properties (Wu et al., 2015). It has been proven that miRNAs participate in the regulation of the development and regeneration of skeletal muscle (Gambardella et al., 2010). With new developments in miRNA analysis and high-throughput sequencing technology, several large-scale miRNA expression studies have been performed. miR-1 and miR-206 are muscle-specific miRNAs with same seed sequences, which indicates that they belong to the same family. Several studies have shown that the seed sequences of these miRNAs could combine with their downstream target genes, $\mathrm{Cx} 43$ and HDAC4, inhibiting the translation of mRNA, thereby, affecting the myogenic differentiation of skeletal muscle satellite cells (Boettger et al., 2014; Yin et al., 2014). However, most of the previous studies involved models, with severe muscle injury caused by drug injection, as research objects; only few studies on the correlation between satellite cells and expression changes of miRNAs implicated in the repair of exercise-induced minor muscle injury have been reported (Liu et al., 2007; Hirai et al., 2010). Based on the "Armstrong's downhill run training model" of rats (Armstrong et al., 1983), we established an exercise scheme and studied the functions of miRNAs (miR-1 and miR-206) and their downstream target genes in the repair of exercise-induced injury in rats.

Genetics and Molecular Research 15 (3): gmr.15038698 


\section{MATERIAL AND METHODS}

\section{Experimental subjects}

Ninety, two-month-old, healthy male Sprague-Dawley rats weighing $252.03 \pm 10.89$ g were included in the study. The rats were kept in different cages with each cage containing five rats; all the rats were fed national standard solid dry fodder for rodents and provided water ad libitum. The cages were housed at $\sim 20^{\circ}-22^{\circ} \mathrm{C}$ under $\sim 50-55 \%$ relative humidity and were illumined from 8:00 a.m. to 8:00 p.m. This study was examined and approved by the Ethics Committee of Mianyang Normal University.

\section{Experiment methods}

\section{Experimental groups}

For six days before the commencement of the experiment, all the rats took five-minute run training once a day at the rate of $10 \mathrm{~m} / \mathrm{min}$; the gradient of the training surface was $0^{\circ}$. The rats that failed to complete the training were excluded from the study. The remaining rats were randomly divided into the static control group, 0-h, 6-h, 12-h, 1-day, 2-day, 3-day, 1-week, and 2 -week groups, with each group comprising 10 rats.

\section{Exercise scheme}

According to the Armstrong's downhill run training model, except for the rats in the static control group, those in the other eight groups took acute run training for $90 \mathrm{~min}$ at a speed of $16 \mathrm{~m} / \mathrm{min}$; the gradient of the training surface was $-16^{\circ}$.

\section{Animal sampling}

Except for the static control group, sampling was performed on the rats in the other eight groups, 0, 6, and $12 \mathrm{~h}, 1,2$, and 3 days, and 1 and 2 weeks after the exercise. Each rat was anesthetized by a peritoneal injection of $10 \%$ chloral hydrate $(45 \mathrm{mg} / 100 \mathrm{~g})$. Thereafter, gastrocnemius muscles from both sides were removed quickly and washed with $0.85 \% \mathrm{NaCl}$ solution; the left muscle was put in paraformaldehyde whereas the right muscle was kept frozen in liquid nitrogen.

\section{Hematoxylin-eosin $(H \& E)$ staining of muscle tissue}

Frozen muscle tissue was thawed by flushing with water for $5 \mathrm{~min}$. The tissue was then trimmed into $0.4 \times 0.3 \times 0.2 \mathrm{~cm}^{3}$ blocks and dehydrated using an alcohol gradient; thereafter, xylene (Dongguan Xinxing Chemical Co., Ltd., Dongguan City, Guangdong Province, China) and paraffin (1:1) were added to the tissue, followed by incubation for $20 \mathrm{~min}$ at $60^{\circ} \mathrm{C}$ in an oven. The tissue blocks were embedded transversely in paraffin and then cut into 5- $\mu \mathrm{m}$ thick slices; after spreading and baking, the glass slides carrying the tissue slices were collected by dyeing frame and kept at $37^{\circ} \mathrm{C}$ in an oven.

The tissue slices were taken out from the oven and sequentially treated with xylene, 
anhydrous ethanol, 95\% ethanol, and 85\% ethanol (Dongguan Xinxing Chemical Co., Ltd., Dongguan City, Guangdong Province, China). The slices were H\&E stained for 5 min, flushed with water for $3 \mathrm{~min}$, differentiated using 1\% hydrochloric acid alcohol for $\sim 2-3 \mathrm{~s}$, followed by water flushing and eosin staining for $3 \mathrm{~min}$ each. The slices were then treated once with $85 \%$ ethanol for $3 \mathrm{~min}$, twice with $95 \%$ ethanol for $3 \mathrm{~min}$, twice with anhydrous ethanol for $3 \mathrm{~min}$, and once with xylene for $3 \mathrm{~min}$; neutral gum was used for sealing the slides, which were then dried at room temperature in a clean darkroom. The cell form and structure of the gastrocnemius muscles were observed under an optical microscope and photographed.

\section{Detection of expression of miRNAs and $m R N A s$ of target genes by reverse transcription-polymerase chain reaction}

A piece of tissue $(1 \mathrm{~g})$ was put into a $2-\mathrm{mL}$ centrifuge tube, and $1 \mathrm{~mL}$ TRIzol (Shrek Biological Technology Co., Ltd., Shanghai City, China) was immediately added to it; two steel balls $(5 \mathrm{~mm})$ were also put in the tube to aid in homogenization, which was performed using a QIAGEN tissue homogenizer. The steel balls were subsequently removed and the homogenate was kept at room temperature for 3-5 min. Thereafter, $200 \mu \mathrm{L}$ chloroform was added to the centrifuge tube for each milliliter of TRIzol used and was thoroughly mixed by shaking. RNA was extracted as per the manufacturer's protocol. RNA was quantitated using an ultraviolet spectrophotometer by measuring the absorbance at $260 \mathrm{~nm}$. An optical density of 1 was assumed to correspond to an RNA concentration of $40 \mu \mathrm{g} / \mathrm{mL}$.

Reverse transcription-polymerase chain reaction (RT-PCR) was performed as follows: First, RT was performed at $16^{\circ} \mathrm{C}$ for $30 \mathrm{~min}$ with Moloney murine leukemia virus reverse transcriptase, and then the RT reaction product was PCR amplified. Table 1 shows the components of the reaction mixture for PCR; they were added in the order shown in the table.

\section{Table 1. Components of the reaction mixture for PCR.}

\begin{tabular}{l|c}
\hline Components & Quantity \\
\hline $\mathrm{H}_{2} \mathrm{O}$ & $7 \mu \mathrm{L}$ \\
\hline 2X QPCR mix (Qiagen) & $10 \mu \mathrm{L}$ \\
\hline Forward primer (10 pM) & $1 \mu \mathrm{L}$ \\
\hline Reverse primer (10 pM) & $1 \mu \mathrm{L}$ \\
\hline Template & $1 \mu \mathrm{L}$ \\
\hline
\end{tabular}

The PCR conditions were as follows: $95^{\circ} \mathrm{C}$ for $2 \mathrm{~min}$, followed by 40 cycles at $94^{\circ} \mathrm{C}$ for $10 \mathrm{~s}, 60^{\circ} \mathrm{C}$ for $10 \mathrm{~s}$, and $72^{\circ} \mathrm{C}$ for $40 \mathrm{~s}$.

\section{Western blot analysis of protein expression from miRNA target genes}

Total protein was extracted from the tissue by trituration of tissue blocks $(1 \mathrm{~g})$ in a cell pulverizer using $100 \mu \mathrm{L}$ cell protein extraction liquid; after dissociation for $10 \mathrm{~min}$ on ice, the lysate was collected in a $1.5-\mathrm{mL}$ Eppendorf tube and centrifuged at $4^{\circ} \mathrm{C}$ for $15 \mathrm{~min}$. The supernatant, thus obtained, was removed as the protein extract and was cryopreserved in Eppendorf tubes in a deep freezer at $-70^{\circ} \mathrm{C}$. The protein concentration was measured using folin-phenol method. 


\section{Statistical analysis}

The experimental data were processed using the statistical package for the social sciences (SPSS) version 18.0, and are presented as mean \pm standard deviation. One-way analysis of variance (ANOVA) was applied for between-the-groups comparison. A value of $P$ $<0.05$ was considered to denote a statistically significant difference.

\section{RESULTS}

\section{H\&E staining of gastrocnemius muscle}

Figure 1A-I show H\&E stained transections of gastrocnemius of rats in the different groups. In the control group (group C), muscle fibers appeared as polygons with cells arranged closely in a regular form, muscle cell membrane was integrated, and the cell nucleus was located beneath the muscle membrane. Compared to group C, round-shaped cellular swellings and increased intercellular spaces were observed in the muscles of rats of the 0-h group. In 6and 12-h groups, muscle cells continued to swell, intercellular distance decreased slightly (in comparison to group C), and the nuclei tended to gather locally. In the 1-day and 2-day groups, cells continued to swell. In the 3-day group, cell swelling was most serious, intercellular spaces increased, and inflammatory cell infiltration indicated the presence of injury. A week after exercise, inflammatory cell infiltration was observed to reduce. Two weeks after exercise, the cell form and structure returned to normal, attaining the regular polygonal shape and new muscle fibers were observed, suggesting that the repair process was almost complete.

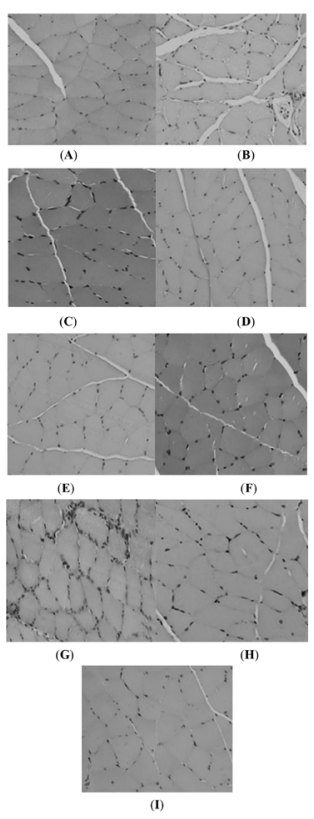

Figure 1. A-I. H\&E stained transections of gastrocnemius of rats in the different groups; in the order of $\mathbf{A}$ to $\mathbf{I}$, the figures are the transections of gastrocnemius of rats in Group C, 0-h, 6-h, 12-h, 1-day, 2-day, 3-day, 1-week and 2-week groups, respectively.

Genetics and Molecular Research 15 (3): gmr.15038698 


\section{Changes in the expression of muscle specific miRNAs in the skeletal muscles of rats during injury repair process}

Figure 2 shows the changing trend in the relative expression of muscle specific miRNAs in the gastrocnemius of rats during different stages after exercise-induced injury. In comparison to the control group, the overall expression changes of muscle-specific miR-1 were not obvious after exercise; initially, there was a slight decrease but after 6,12 , and $24 \mathrm{~h}$, the expression increased gradually. The differences in the results of the control and other groups were not significant $(P>0.05)$. Figure 3 shows the changing trend in the relative expression of miR-206 in the gastrocnemius of rats of each group. In comparison to the control group, the overall expression of miR-206 showed an increasing trend after exercise; two weeks later, the expression returned to normal levels. Compared to the static control group, only the results obtained in the rats of the 1-week group were significantly different $(\mathrm{P}<0.05)$.

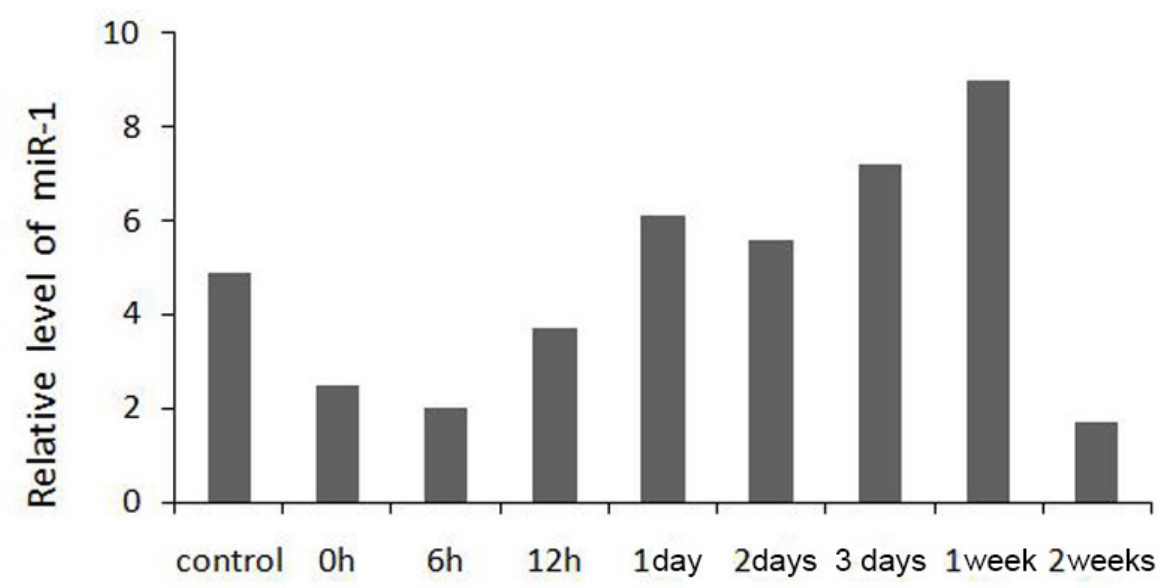

Figure 2. Relative expression of miR-1 in rats of different groups.

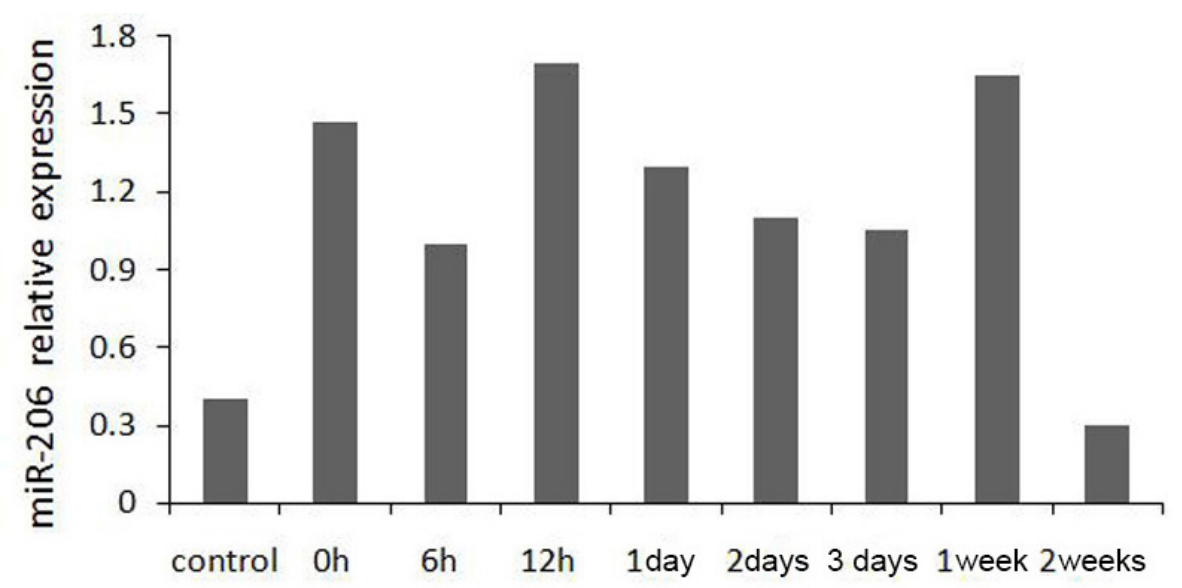

Figure 3. Relative expression of miR-206 in rats of different groups. 


\section{Changes in the expression of target genes of muscle specific miRNAs}

Figure 4 shows the changes in the relative expression of mRNAs in the gastrocnemius of rats during the different stages after exercise-induced injury. Compared to the control group, immediately after exercise, mRNA expression of Cx43 and HDAC4 genes was observed to first decrease and then increase gradually. The differences in HDAC4 mRNA expression after exercise were significant in the 1 -week group $(\mathrm{P}<0.05)$, whereas the differences in mRNA expression of $\mathrm{Cx} 43$ were not significant between the groups $(\mathrm{P}>0.05)$.

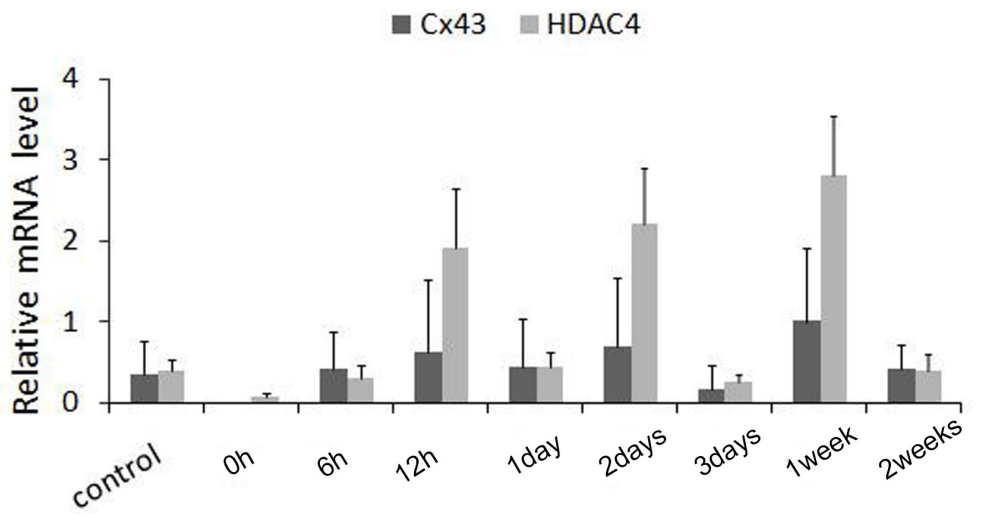

Figure 4. Changes in the relative mRNA expression levels of $\mathrm{Cx} 43$ and HDAC4 genes in the gastrocnemius of rats in the different groups.

Western blots revealing the expression of the target proteins are shown in Figure 5. In comparison to the control group, expression of $\mathrm{Cx} 43$ and HDAC4 proteins decreased quickly in the 0 -h group. Thereafter, the expression in each group gradually increased back to the normal levels. Three days after exercise, the expression of proteins showed an obvious decrease. Figure 6 shows the relative expression levels of the two proteins in the gastrocnemius of rats in the different groups. In comparison to the control group, differences in the $\mathrm{Cx} 43$ protein levels between the 0 -h and 3 -day groups were significant $(\mathrm{P}<0.05)$. After exercise, the HDAC4 protein levels in each group showed no significant difference $(\mathrm{P}>0.05)$.

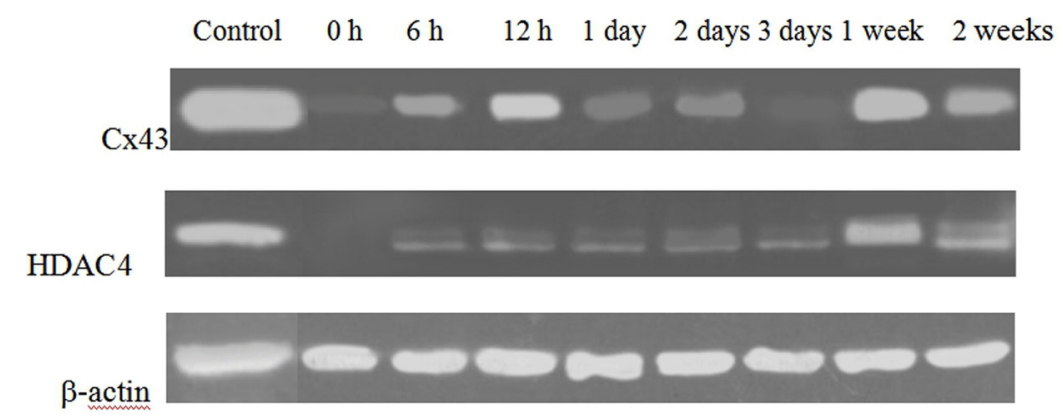

Figure 5. Western blots showing the $\mathrm{Cx} 43$ and HDAC4 expression.

Genetics and Molecular Research 15 (3): gmr.15038698 


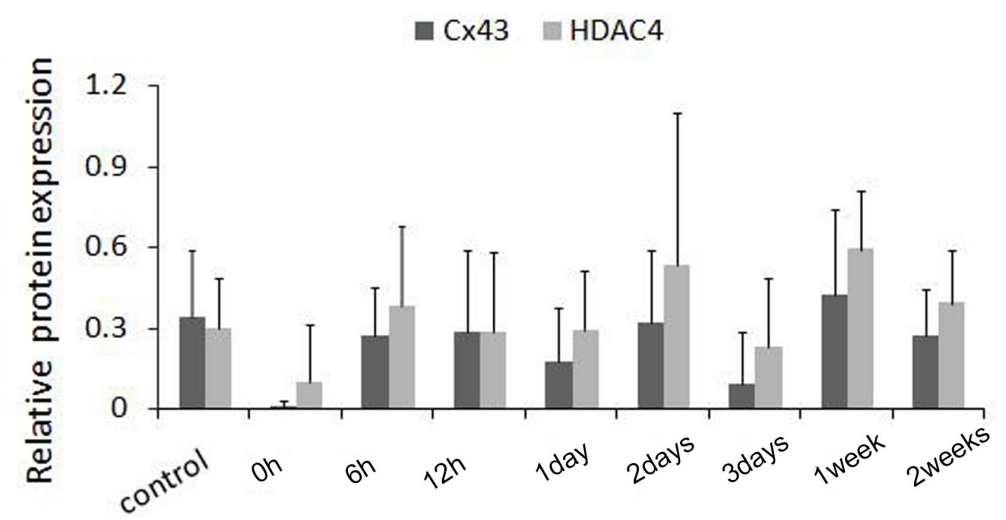

Figure 6. Relative expression levels of $\mathrm{Cx} 43$ and HDAC4 in the gastrocnemius of rats in the different groups.

\section{DISCUSSION}

\section{Repair model of exercise-induced injury in the skeletal muscles of rats}

In previous studies, most researchers have adopted the skeletal muscle injury model in rats, which were obtained by injecting a dose of drug. However, in sports practice, exercise intensity and load settings do not cause muscle injury similar to that caused by drug injections. Accordingly, in the present study, we adopted a continuous downhill run training to achieve skeletal muscle injury in rats. It has been reported that exercise-induced skeletal muscle injury is a kind of micro-injury of skeletal muscle fibers caused due to high-strength and/or longterm exercise (Cressoni et al., 2008); in such cases observing the morphological and structural changes in the skeletal muscle cells was the most direct and reliable method for evaluation of the injury (Dugan et al., 2010). In this study, using H\&E staining, we observed slight swelling of muscle cells and inflammatory cell infiltration in gastrocnemius after the exercise; the injury was most serious, three days after the exercise; two weeks after exercise, the normal form of muscle fibers mostly recovered and inflammatory infiltration disappeared, and the cells were arranged closely. The model adopted in this study had imposed micro-injury in the muscle. Therefore, in the repair process, the morphological results were different from that of the injury caused by drug injection; the form differences were reflected in the muscle injury area and the location of nucleus during the repair period. Our results confirmed that the repair model for exercise-induced micro-injury in muscles was successful. Different from the models of muscle injury caused by drug injection, the micro-injury model proposed in this paper was more representative of the exercise-induced muscle injury.

\section{Participation of miRNAs in the repair of exercise-induced muscle injury}

The repair of muscle injury is a complex and dynamic process. Satellite cells are the main stem cells that participate in muscle repair, which are usually located between the basement membrane and myolemma of the muscle fibers in a resting state (Chakkalakal et al., 2012). They start to proliferate after muscle injury. In the early differentiation period, myoblasts are expressed as myogenin; and then, they turn into multicore myotubes to repair the injured

Genetics and Molecular Research 15 (3): gmr.15038698 
skeletal muscle. Increasing number of researches on skeletal muscles have demonstrated that miRNAs play important roles in regulating the repair of muscle injury, the biological state of satellite cells, and muscle diseases (Finch et al., 2014).

In this study, the gastrocnemius of rats was used for the experiments. The results demonstrate that the overall range of expression of muscle specific miR-1 was not great in the repair process of exercise-induced muscle injury; however, the expression of miR-206 was observed to increase. In contrast to the studies performed by Chen et al. (2010) and Liu et al. (2012), the present study adopted a different experimental subject, animal species, and sampling parts; however, the main cause of the differences in results might be the various inducing factors that caused different degrees of injury to the skeletal muscle, thereby causing different changes in the expression of muscle specific miRNAs. It was normal for the exerciseinduced muscle injury model adopted in this study to have non-obvious changes in the expression of miRNAs owing to the low degree of injury. It was found that miR-1 expression decreased slightly in the 0-h group after exercise; its expression increased slightly in the 6-, 12-, and 24-h groups. In comparison to the static control group, the differences in the results of the repair process were not significant. Presumably, the role of miR-1 in the repair process of exercise-induced muscle injury may not be very important. In the $0-, 6-$, and 12 -h groups, expression of miR-206 continued to rise after exercise, and the overall expression showed an increasing trend; in the 1-week group, the statistical results showed significant differences, indicating that miR-206 might be more involved in the repair process after exercise-induced skeletal muscle injury.

\section{Role of muscle-specific miRNAs in muscle regeneration after exercise-induced injury}

$\mathrm{Cx} 43$ is a basic cellular protein that constitutes the gap junction of skeletal muscle fibers. This suggests that the amount of $\mathrm{Cx} 43$ directly affects the structure of gap junction between the muscle cells and further affects the exchange of message between the muscle tissue cells (Dey et al., 2011). Through studies on in vitro cultured myoblasts, Anderson et al. (2006) confirmed that miR-1 and miR-206 regulated the process of muscle generation without influencing the Cx43 mRNA expression levels. In this study, it was observed that the changing trend of $\mathrm{Cx} 43 \mathrm{mRNA}$ was consistent with that of the protein expression; the trend of HDAC4 mRNA and protein expression was similar to that of $\mathrm{Cx} 43$. In view of previous studies (Haberland et al., 2009), two kinds of muscle specific miRNAs are known to regulate the repair process of skeletal muscle injury by inhibiting the expression of downstream target genes. In the present study, the miR-206 expression was observed to increase in comparison to the expression in the control group. In the 1-week group, the increase in expression was significant after the exercise, indicating that miR-206 played an important role in the exerciseinduced injury repair process.

In the present study, we observed that the expression of $\mathrm{Cx} 43 \mathrm{mRNA}$ and protein showed a declining trend in the 0 -h and 3-day groups compared to the control group; the differences in protein expression were significant. The significant differences in the expression of downstream target genes of miRNAs in the 0 -h and 3-day group suggested that $\mathrm{Cx} 43$ was probably involved in the repair process of exercise-induced injury in rat gastrocnemius. Moreover, the changes in expression were more obvious in the occurrence phase of exerciseinduced injury. Given the morphological observations reported in this paper, we found that the intercellular space in the gastrocnemius of the rats in the 0-h group started to grow, which

Genetics and Molecular Research 15 (3): gmr.15038698 
would affect the transmission of messages between the cells. It could be determined that the increase in intercellular space was also reflected by a sharp decline in the $\mathrm{Cx} 43$ protein levels. The Cx43 expression declined rapidly in the 0 -h group, which probably resulted from the adaptive influence of acute exercise-induced changes in the cellular state of rat muscles on the intercellular communication, thus, inhibiting the transcription and translation of $\mathrm{Cx} 43$. In the 6-h, 12-h, 1-day, and 2-day groups, there was no significant difference in the mRNA and protein expression, which was probably an adaptive adjustment of the body for recovery and stability after exercise. In the 3-day group, morphological observations revealed that muscle injury was in the most serious period. Accordingly, it could be presumed that the decrease in Cx43 mRNA and protein expression might be caused by structural damage of the muscle cells. In the 1-week group, the expression of $\mathrm{Cx} 43 \mathrm{mRNA}$ and protein began to rise, which might have enhanced the transmission of message between the damaged fibers and the differentiated and proliferated satellite cells, thereby, promoting the repair of muscle injury.

In conclusion, based on skeletal muscle repair model after exercise-induced microinjury in rats, we found that the changes in the expression of muscle specific miR-1 were not obvious in the repair process of exercise-induced injury in gastrocnemius of rats, whereas the expression of miR-206 showed an increasing trend; the changes in the expression of its downstream target gene $\mathrm{Cx} 43$ were significant in the 0 -h and 3-day groups after exercise, indicating that miR-206 might participate in the repair process of the injured gastrocnemius in rats through the regulation of $\mathrm{Cx} 43$ expression.

\section{Conflicts of interest}

The authors declare no conflict of interest.

\section{REFERENCES}

Anderson C, Catoe H and Werner R (2006). MIR-206 regulates connexin43 expression during skeletal muscle development. Nucleic Acids Res. 34: 5863-5871.http://dx.doi.org/10.1093/nar/gkl743

Armstrong RB, Ogilvie RW and Schwane JA (1983). Eccentric exercise-induced injury to rat skeletal muscle. J. Appl. Physiol. 54: 80-93.

Boettger T, Wüst S, Nolte H and Braun T (2014). The miR-206/133b cluster is dispensable for development, survival and regeneration of skeletal muscle. Skelet. Muscle 4: 23. http://dx.doi.org/10.1186/s13395-014-0023-5

Braun T and Gautel M (2011). Transcriptional mechanisms regulating skeletal muscle differentiation, growth and homeostasis. Nat. Rev. Mol. Cell Biol. 12: 349-361.http://dx.doi.org/10.1038/nrm3118

Chakkalakal JV, Jones KM, Basson MA and Brack AS (2012). The aged niche disrupts muscle stem cell quiescence. Nature 490: 355-360.http://dx.doi.org/10.1038/nature11438

Chen JF, Tao Y, Li J, Deng Z, et al. (2010). microRNA-1 and microRNA-206 regulate skeletal muscle satellite cell proliferation and differentiation by repressing Pax7. J. Cell Biol. 190: 867-879. http://dx.doi.org/10.1083/ jcb.200911036

Cressoni MD, Dib Giusti HH, Casarotto RA and Anaruma CA (2008). The effects of a 785-nm AlGaInP laser on the regeneration of rat anterior tibialis muscle after surgically-induced injury. Photomed. Laser Surg. 26: 461-466. http:// dx.doi.org/10.1089/pho.2007.2150

Davis TA and Fiorotto ML (2009). Regulation of muscle growth in neonates. Curr. Opin. Clin. Nutr. Metab. Care 12: 7885. http://dx.doi.org/10.1097/MCO.0b013e32831cef9f

Dey BK, Gagan J and Dutta A (2011). miR-206 and -486 induce myoblast differentiation by downregulating Pax7. Mol. Cell. Biol. 31: 203-214. http://dx.doi.org/10.1128/MCB.01009-10

Dey BK, Pfeifer K and Dutta A (2014). The H19 long noncoding RNA gives rise to microRNAs miR-675-3p and miR-675$5 \mathrm{p}$ to promote skeletal muscle differentiation and regeneration. Genes Dev. 28: 491-501. http://dx.doi.org/10.1101/ gad.234419.113

Genetics and Molecular Research 15 (3): gmr.15038698 
Dixon JB (2009). Gastrocnemius vs. soleus strain: how to differentiate and deal with calf muscle injuries. Curr. Rev. Musculoskelet. Med. 2: 74-77.http://dx.doi.org/10.1007/s12178-009-9045-8

Dugan JM, Gough JE and Eichhorn SJ (2010). Directing the morphology and differentiation of skeletal muscle cells using oriented cellulose nanowhiskers. Biomacromolecules 11: 2498-2504.http://dx.doi.org/10.1021/bm100684k

Finch ML, Marquardt JU, Yeoh GC and Callus BA (2014). Regulation of microRNAs and their role in liver development, regeneration and disease. Int. J. Biochem. Cell Biol. 54: 288-303.http://dx.doi.org/10.1016/j.biocel.2014.04.002

Gambardella S, Rinaldi F, Lepore SM, Viola A, et al. (2010). Overexpression of microRNA-206 in the skeletal muscle from myotonic dystrophy type 1 patients. J. Transl. Med. 8: 48. http://dx.doi.org/10.1186/1479-5876-8-48

Haberland M, Montgomery RL and Olson EN (2009). The many roles of histone deacetylases in development and physiology: implications for disease and therapy. Nat. Rev. Genet. 10: 32-42.http://dx.doi.org/10.1038/nrg2485

Hara M, Yuasa S, Shimoji K, Onizuka T, et al. (2011). G-CSF influences mouse skeletal muscle development and regeneration by stimulating myoblast proliferation. J. Exp. Med. 208: 715-727. http://dx.doi.org/10.1084/jem.20101059

Hirai H, Verma M, Watanabe S, Tastad C, et al. (2010). MyoD regulates apoptosis of myoblasts through microRNAmediated down-regulation of Pax3. J. Cell Biol. 191: 347-365. http://dx.doi.org/10.1083/jcb.201006025

Liu N, Williams AH, Kim Y, McAnally J, et al. (2007). An intragenic MEF2-dependent enhancer directs muscle-specific expression of microRNAs 1 and 133. Proc. Natl. Acad. Sci. USA 104: 20844-20849. http://dx.doi.org/10.1073/ pnas. 0710558105

Liu N, Williams AH, Maxeiner JM, Bezprozvannaya S, et al. (2012). microRNA-206 promotes skeletal muscle regeneration and delays progression of Duchenne muscular dystrophy in mice. J. Clin. Invest. 122: 2054-2065. http://dx.doi. org/10.1172/JCI62656

Maltzahn JV, Bentzinger CF and Rudnicki MA (2014). Characteristics of satellite cells and multipotent adult stem cells in the skeletal muscle. In: Stem cells and cancer stem cells. Springer Netherl. 12: 63-73.

Wu ZW, Liu YF, Wang S and Li B (2015). miRNA-146a induces vascular smooth muscle cell apoptosis in a rat model of coronary heart disease via NF-kB pathway. Genet. Mol. Res. 14: 18703-18712. http://dx.doi.org/10.4238/2015. December.28.19

Yin Y, Shan HQ, Huang W, Wu YM, et al. (2014). Bioinformatic analysis of miRNA expression patterns in TFF2 knockout mice. Genet. Mol. Res. 13: 8502-8510. http://dx.doi.org/10.4238/2014.October.20.26

Genetics and Molecular Research 15 (3): gmr.15038698 